\title{
СООТНОШЕНИЕ КОННОТАТИВНОГО
}

И ДЕНОТАТИВНОГО КОМПОНЕНТОВ

В СЕМАНТИКЕ НЕКОТОРЫХ ГРУПП

АБСТРАКТНОЙ ЛЕКСИКИ И В СЕМАНТИКЕ

ЛЕКСЕМ ТЕМАТИЧЕСКОЙ ГРУППЫ ЗООНИМОВ

(на примере зоонима «Корова»)

\section{П.Ю. Красильникова}

Аннотация. В лингвистике существуют разнье представления о соотношении денотативной и коннотативной сторон значения слова. Неслотря на то, что дополнительная контекстуальная селантика, как правило, илеет больший инфбормационный объел, коннотативные значения неизленно воспринилаются как второстепенные по отношению к денотативньлм. Очевидно, что присутствует законолерность, связываюшая денотаиию с бборлирующейся на ее основе коннотацией. В данной статье расслатривается разница коннотаций достаточно далеких друг от друга, с точки зрения степени конкретности слов именной лексики, обозначаюшей абстрактные понятия, и конкретных существительных телатической группь зоонилов. Результатол сравнения является вывод о соответствии объела коннотаиии и денотации как обратно пропорииональной зависилости: чел уже область денотации, тел больше качественный и количественный потенииал слова к развитию коннотативного значения, и наоборот - чел пышнее в денотации букет селантических элелентов, связанных с элоцияли, оценкали и представленияли о нелатериальной стороне мира, тел меньше у лексель возложностей для фборлирования дополнительных значений вне определенных вторичных моделируюших систел.

Ключевые слова: коннотативная селантика абстрактной лексики, коннотативная селантика зоонилов, виды денотата, диналика развития коннотации, язык художественной литературы. 
CORRELATION OF CONNOTATIVE AND DENOTATIVE COMPONENTS IN THE SEMANTICS OF SOME GROUPS OF ABSTRACT VOCABULARY AND IN THE SEMANTICS OF ZOONYMS (On the Example of the Word "Cow")

\section{P.Yu. Krasilnikova}

Abstract. In linguistics, there are different ideas about the ratio of the denotative and connotative sides of the meaning of a word. Despite the fact that additional contextual semantics, as a rule, has a larger information volume, connotative meanings are invariably perceived as secondary to denotative ones. Obviously, there is a pattern linking denotation with the connotation formed on its basis. The article considers the difference in connotations of quite distant from each other in terms of the degree of concreteness of words nominal vocabulary denoting abstract concepts, and specific nouns of the thematic group of zoonyms. The result of the comparison is the conclusion about the correspondence of the volume of connotation and denotation as an inversely proportional dependence: the narrower the area of denotation, the greater the qualitative and quantitative potential of the word to develop connotative meaning, and vice versa - the more magnificent the bouquet of semantic elements associated with emotions, ratings, and ideas about the non-material side of the world, the less the lexeme has opportunities for the formation of additional values outside certain secondary modeling systems.

Keywords: connotative semantics of abstract vocabulary, connotative semantics of zoonyms, types of denoter, dynamics of development of connotation, language of fiction.

$\mathrm{O}$ тношения коннотации и денотации слова при употреблении не могут рассматриваться вне связи с общей характеристикой их потенциального семантического объема, так как свойства коннотации, как представляется, находятся в зависимости от особенностей денотации. Мы предполагаем, что коннотация, как таковая, появляется у того или иного слова в момент пересечения с обозначаемым им объектом или явлением определенного порога значимости для языкового сознания. Значимость эта может быть как практической (относи- тельно практической, ведь поклонение тотему племени тоже несло для исполняющих его чисто практический смысл), так и эмоциональной.

Слова могут быть разделены на группы по виду их денотатов. Мы воспользуемся классификацией Н.Г. Комлева, чтобы описать закономерности в соответствии денотативных сторон значения свойствам коннотации. Сначала ученый противопоставляет объектам языкового характера объекты внеязыковой действительности. Слова первой группы - это, вопервых, мета-лексика, означающая 
языковые акты, к ней же относятся и универсальные слова, сохранившие внеязыковую редеренцию, например, туланный (выражение и воздуx), грубый (слово и поведение), вовторых, фоннциональная лексика, обозначающая исключительно языковые отношения: предлоги, союзы, местоимения и др. Их денотаты языковые фракты и отношения [1, c. 84]. Объекты внеязыковой действительности, к которым отсылает денотативная семантика слов, разделяются на три вида: телесные, френоменальные и конструктные. Конструктные объекты составлены из фррагментов реальности, соотносятся с франтастическими представлениями и пустыми классами, они «образуют мысль, которая и служит объектом языкового обозначения» [там же, с. 86], например, кентавр, ведьла, естественный спутник Луны. Феноменальными объектами являются некоторые свойства телесных объектов, их действия, качества и отношения.

Понимая под самим фактом коннотированности противопоставление денотации, следует признать, что, например, для слов, обозначающих чувства и оттенки человеческих чувств, проблема разграничения разных компонентов значения лексемы не может иметь полноценного решения как таковая. Эта мысль продиктована неопределенностью денотата, следовательно, и лабильностью всех сторон семантики слова. То есть, если исходить из представления о формировании коннотации из увеличения значимости, то слова, называющие состояния души человека и незримые абстракции, являются скорее названием суммы коннотаций, суммы оттенков значений одного неопределимого понятия. Говоря об упомянутой классификации денотатов, Н.Г. Комлев также отмечает, что в ней «неясное место занимают объекты интроспективной психической жизни» [там же, с. 87]. В семантике лексем этого типа более значительная часть содержания приходится на рациональный сигнификативный слой, а не на конкретно-чувственный денотативный, который может быть и пустым. Нам кажется, что характеристику класса «объекты интроспективной психической жизни» можно несколько уточнить. Так, лексемы, обозначающие черты характера человека, никогда не бывают лишены оценочного компонента семантики, причем он даже не редрлексируется как оценка, так как общественному сознанию, «здравому смыслу", очевидно, что инертность, лень, недоброжелательность это плохо, а энергичность, легкость характера, снисходительность хорошо. Томас Манн писал в романе «Волшебная гора»: «К сожалению, когда мы говорим о тех или иных особенностях характера, в наших словах всегда скрыта моральная оценка, либо хвала, либо порицание, хотя у каждой такой особенности всегда есть две стороны» [2, с. 161]. Предполагаем, что это свидетельствует о соответствующем свойстве общего человеческого образа мира, делающем наиболее доступными для оценивания именно людей и требующем непременной квалификации их качеств согласно усредненным представлениям о прекрасном, здоровом и разумном.

Совсем иначе с точки зрения коннотативного содержания выглядят языковые способы выражения и опи- 
сания состояний души, как и соответствующие этим состояниям ритуалы культуры (оплакивания, поздравления и т. п.), будучи закреплены в определенной рациональной форме, имеют мало отношения к содержанию чувства. Так, рассуждая о слагаемых ритуала скорби, М. Мамардашвили говорит: «они, действуя на человеческое существо, переводят, интенсифицируя, его обычные состояния в другой режим жизни и бытия, в тот режим, в котором уже есть память, есть преемственность, есть длительность во времени, не подверженные отклонениям и распаду (которым они были бы подвержены, если бы были предоставлены естественному ходу самих натуральных процессов). Мы помним, мы любим, мы привязаны, имеем совесть (эти чисто человеческие состояния), когда мы прошли, как мясо, через формообразующую или делающую фарш машину» [3, с. 17-18]. Этот тезис относится к философии сознания в большей степени, чем к языковой семантике, но и с точки зрения лингвистики «именно представления помогают вопринимать и удерживать в памяти абстрактные лексические понятия, например, такие, как вреля, сила, дуx и т.д.» [1, с. 111]. Целью изучения любой знаковой системы является определение ее содержания. Реальное же содержание называемых словами чувств никакими научными методами проанализировано быть не может, но лингвистическая сторона этого вопроса, естественно, может иметь решение, связанное с рассмотрением существующих языковых структур, а не гипотетических построений, «потому что любая попытка детерминистского осознания начальных условий уже содержит в себе в скрытом виде сами эти начальные условия <..> генетически предшествующее начальное условие не восстановимо» [4]. Невозможен даже метаязык для содержательного описания тех оттенков чувств, проявляющихся в человеке вне традиционного контекста употребления таких слов, как боль, тоска, любовь, т. е., они создают свои значения сами, входя в концептуальную картину мира человека с детства и регулируя его представления о себе и мире всю жизнь.

Очень примечателен в этом контексте миф о древнеиндийской богине речи Вач, кратко изложенный В.Н. Топоровым. В посвященном ей гимне она описывает себя сама и сама же называет свое имя в анаграмме. «В. выше неба и шире земли. Она - владычица и собирательница богатств, наделяет ими всех; кого она любит, тот становится сильным, мудрым <..> Она порождает споры между людьми и насыщает тех, кто слышит сказанное ею. <..> Ее называют божественной, царицей богов. <..> Шат.-бр. говорит о ней как об одной из жен Праджапати, создавшего воды из мира в образе речи. <..> Образ В. сложился на основе др.-инд. представлений о триаде мысль-слово-дело» [5, т. 1, с. 7273]. Представляется, что современные лингвистические концепции также регулируются рамками, метафорически присутствующими в этом описании речи, - она говорит о себе сама, человек не может рассуждать о себе и своем мире вне языка, не может подняться над водами речи, потому что они всегда текут внутри него самого. 
В толковании сложных понятий, выраженных, например, абстрактными существительными, не имеющими вещественного значения, вопрос о разграничении языка-объекта и языка метаописания не представляется разрешимым. Если неопределима область денотации, то и суждение об объеме и границах коннотации вызывает сомнения, само разделение этих макрокомпонентов в структуре значения до какой-то степени условно.

Единственная область, в рамках которой возможно говорить о коннотациях подобных лексем - вторичные моделирующие системы художественного, этического, идеологического или иного типа [6, с. 23]. Коннотативные элементы развиваются на основе денотации в результате включения слова в определенные отношения с другими элементами вторичной моделирующей системы. Так, М.Ю. Лотман приводит яркий пример вычленения контекстуальной коннотации лексемы гений, называемой им "значением понятия в системе романтизма» [там же, с. 25], на основе антитезы гений-толпа, накладывающейся на оппозиции величие/ничтожество, исключительность и необычность/пошлость и заурядность, духовность/материальность, творчество/животность, мятеж/покорность и т. п. То есть, все первые и все вторые члены оппозиций являются «вариантами некоего архизначения» [там же, с. 26], которое для нас и становится направлением и характером актуальной коннотации этих лексем. «Значение элементов возникает в их отношении» [там же, c. 29], а для исследования коннотации отношение таких лексем, как аб- страктные существительные друг к другу позволяет не только наблюдать проявление их значения, но и разделять коннотативный и денотативный макрокомпоненты значения, и анализировать содержание этих компонентов. Однако нельзя упускать из виду тот фракт, что реляционные элементы значений по очевидным причинам не должны без дополнительного рассмотрения переноситься в другие системы, т.е. они остаются актуальными только в рамках своей или схожих вторичных моделирующих систем. Так, слова тоска, тревога, тщета, отчаяние, могут иметь функционально-стилистически ограниченное употребление, могут характеризоваться определенной традицией использования, однако структурные вопросы внеконтекстуальной коннотированности для лексем такого рода не могут быть решены, как мы уже отмечали выше, из-за их в буквальном смысле слова метафизической отнесенности, т. е. умозрительности денотации.

Не менее интересен вопрос соотношения сторон языкового знака применительно к чисто оценочным словам, принадлежащим к разным частям речи. Точный и не требующий доказательств ответ на вопрос «Что такое хорошо и что такое пло$x o$ ?» возможен только в таком виде: это антонимичные друг другу слова (наречия, краткие прилагательные или слова категории состояния), соответствующие противоположным точкам на оценочной шкале. Человек с рождения слышит характеристики чего-либо в рамках этой оппозиции и считает ее полностью реальной и доступной для осмысления, хотя сама оппозищия не существует 
нигде, кроме как в языке. Существует, конечно, и крайность в стремлении относить даже самые ясные из основных значений к условным «по примышлению - сладкое, по примышлению - горькое, а в действительности атомы и пустота» [3, с. 89], но мы ограничимся выводом об отсутствии у абстрактных слов возможности развивать полноценную систему коннотативных значений, так как их лексическое значение уже перенасыщено примышлением большого количества разнородных признаков. Так, слово горе не имеет собственных коннотаций, присущих ему вне контекста, в него включен неизмеримо широкий и детализированный диапазон человеческих чувств и оценок, которые сами по себе и являются источников коннотированности в языке, но фрразеологизм горе луковое, где этот диапазон сужен благодаря иронической окраске, уже может реализовывать в контексте дополнительные оттенки значения.

Совершенно иная природа семантики у тех лексико-семантических групп существительных, которые обозначают предметы и явления, близкие человеку в период становления языковой традиции. К ним относятся пространственные характеристики, явления и объекты неживой природы, растения, животные, элементарные предметы обихода, части человеческого тела и детали облика (невербальные средства коммуникации). Коннотативная семантика этих слов очень богата, имеет по большей части культурную обусловленность и, в отличие от абстрактных существительных, определенным образом прямо или косвенно связана с денотатом (по
Н.Г. Комлеву, телесные объекты занимают главенствующее положение среди объектов внеязыковой действительности по признаку бесспорной и очевидной связи денотата со словом-знаком [1, с. 84]). Даже полностью, казалось бы, нейтральные понятия ориентационных признаков имеют сложную систему сопутствующих значений, что подробно описано в 4 главе известной книги «Метадоры, которыми мы живем» Дж. Лакофрда и М. Джонсона [7, с. 35-46].

Мы не ставим цели тщательно анализировать коннотативную нагруженность всех частей речи и лексико-семантических групп, но и при поверхностном рассмотрении становится очевидной перспектива плодотворного изучения системы дополнительных культурных коннотаций именно той лексики, с предметами номинации которой у языкового сознания самые долгие и самые глубокие отношения. Человеческая франтазия и способность к абстрактному мышлению способствовала развитию сложной культуры, в языке эта динамика отразилась на всех уровнях, на грамматическом - в виде появления грамматических категорий, изменении и усложнении структуры предложения, на лексическом уровне - имплицитно, в форме разветвленной коннотативной системы слов. Лексемы, обозначающие доступные человеку для осмысления объекты, вобрали в свою семантику все, что было менее доступным, но привлекало к себе внимание, опережая позитивное знание происходящего в мире. Так, слова, обозначающие человеческое тело и его части впитали в свою коннотативную семантику не только представления 
обо всех процессах мироздания, но и о происхождении всего сущего, что воплотилось, например, в мифе о первочеловеке Пуруше. Лексико-семантическая группа зоонимов, выступавшая в давние времена как один из основных мифологических кодов, сохранила в своей активной, т.е. интерпретируемой и сейчас, коннотативной семантике множество элементов - осколков более древних представлений о мире. В этом вопросе преимущество зоонимов перед названиями бытовых предметов и фритонимов обусловлено неязыковыми факторами. Мифические (анимические, демонические, космогонические) представления и коннотации, закрепляющие их фррагменты, сохраняются в языке и мышлении дольше всего. Таким образом, именно коннотации оказываются той частью семантической сореры языка, которая не только вмещает значимые для определенной культуры свойства номинируемого предмета или явления, но, что более важно, позволяет составить представление о том, как и почему у тех или иных языковых коллективов складывалась определенная система ценностей. Элементарным примером в данном случае является слово корова, коннотированное в современном русском языке достаточно узко и несущее пейоративную семантику в переносном значении на основе денотативных признаков крупная, грузная, переосмысляемых с коннотативным оттенком отрицательной оценки, а также чисто коннотативных признаков неловкая, упрялая и т.п. В поэтической речи примеров такого употребления мало по понятным причинам, их можно услышать в разговорной речи человека низкой речевой культуры.

Здесь мы сталкиваемся с любопытной особенностью русского языкового сознания, которая заключается в тенденции к присвоению одомашненным, полезным в хозяйстве животным негативных характеристик, относимых обычно людьми $к$ людям (глупость, нечистоплотность, упрямство, лень и т. п.). Напротив, заимствованные из мифов других народов мифологические представления, которые воплотились, например, в коннотациях, присутствующих во фрразеологизме священная корова (индуизм, джайнизм, зороастризм) и порожденных представлением о небесной корове, отличаются мелиоративными оттенками или отражают нейтральные метафрорические значения: «то, о чем не следует говорить» или «обладание правовым иммунитетом» [8]. Интересно, что такое употребление, основанное на заимствованной мифологии, для языка русской поэзии становится характерным в начале XX века, что, по-видимому, объясняется волной популярности экзотических древних культур и религий Востока среди образованных людей. Сp.

\section{Я смиренная корова;}

Нраву я была простова;

Грех мой, право, не велик:

Ободрал меня мясник

(В.А. Жуковский, 1815) [9];

Один из них был тот, чей бык налнясь пропал,

Другой, - корова чья налнясь c двора пропала

(А.П. Сумароков, 1755) [9];

Зашла раз корова к отиу за погост, Махнул я ее через крышу за хвост (А.К. Толстой, 1867) [там же]; 


\section{И}

Быкк на иепи золотой,

$B$ небе высоко ревет...

Вон и корова пльвет

(А.Н Толстой, 1909) [там же];

Стихни, ветер,

Не лай, водяное стекло.

С небес через красные сети

Дождит молоко.

Мудростью пухнет слово,

Вязью колося поля,

Над тучали, как корова,

Хвост задрала заря

(С.А. Есенин, 1917) [там же];

И Великий Сбинкс, как корова,

На Сахару прольет удой

(Н.А. Клюев, 1921) [там же].

Наиболее ярко мифопоэтическая образность лексемы корова раскрывается в поэзии Н.А. Заболоцкого:

Я спал, овчиною закутан,

и вдруг открылся небосклон

С большим животнылм институтом.

Тали жизнь былла всегда здорова

И посреди большого зданья

Стояла стройная корова

В венце неполного сознанья

$<\ldots>$

Тали кони, хилии друзья,

Хлебали щи из ста молекул,

Иные, в воздухе висл,

Слотрели, кто с небес приехал.

Корова в борлулах и лентах

Пекла пирог из элелентов,

И перед нею в банке рос

Большой хилический овес

(«Начало науки», 1931) [там же];

Послушайте, деревья, речь

О тол, как появляется корова

(«Пир в доме Бомбеева», 1933) [там же].

Связь с общеиндоевропейскими представлениями о мировом древе особенно отчетливо проявляется в стихотворении Н.А. Заболоцкого «Искусство»:

Дерево растет, наполиная

Естественную деревянную колонну.

Oт нее расходятся члень,

Одетье в круглье листья.

Собранье таких деревьев

Образует лес, дубраву.

Но определенье леса неточно,

Если указать на одно формальное

строенье.

Толстое тело коровь,

Поставленное на четьре окончанья,

Увенчанное хромовидной головою

И двумя рогали (словно луна в первой четверти).

Тоже будет непонятно,

Также будет непостижимо,

Если забудел о его значенье

На карте живуших всего мира.

Дол, деревянная постройка,

Составленная как кладбище деревьев,

Сложенная как шалаш из трупов,

Словно беседка из мертвецов, -

Кому он из слертных понятен,

Кому из живущих доступен,

Если забудел человека,

Кто строил его и рубил?

Человек, владыка планеть,

Государь деревянного леса,

Илператор коровьего мяса,

Саваоф двухэтажного дома, -

Он и планетою правит,

Он и леса вырубает,

Он и корову зарежет,

А вылиолвить слова не может.

Но я, однообразный человек,

Взял в рот длинную сияюшую дудку,

Дул, и, подчиненные дьханию,

Слова вылетали в мир, становясь

предлетали.

Корова мне кашу варила,

Дерево сказку читало, 
A мертвые домики мира

Прыгали, словно живые [там же].

Дерево символизирует общечеловеческую культуру, из него, тем подчинив его бытовой фрункции, было построено множество домов, так же и небесная корова, орошающая мир своим молоком, изменила свою место в иерархии. Образ человека-мясника, разрушившего естественный порядок жизни и расчленившего небесную корову, встречается и в уже упомянутом стихотворении «Пир в доме Бомбеева»:

Послушайте, деревья, речь

О тол, как появляется мясник.

Его топор сверкает, словно меч,

И он к убийству издавна привык.

Еще растеньяли бока коровы полнь, Но уж кровавые из тела хлешут

волны,

И, хлопая глазали, голова

Летит по воздуху, и мертвая корова Лежит в пьли, для щей вполне

готова,

И мускулали двигает едва.

А печка жизни все пьлает,

Горит, трещит элелентал,

И человек ладонью подсыпает

В мясное варево сияющий кристалл.

В желудке нашел исчезают звери,

Животные, растения, иветы,

И печки - жизни выпукльье двери

Для наших мыслей крепко заперть

[там же].

Так как мы считаем основным способом реализации коннотативного значения контекст употребления, мы можем проследить своеобразный графрик глубины и распространенности той или иной коннотации, исходя из частоты и характера ее прояв- ления. Отчасти литературоведческое описание бытования лексемы корова в поэтических текстах служит для демонстрации параметра глубины, который к первой четверти XX века достиг своего максимального значения, т. е. структура и свойства мифопоэтического образа реализовались в контекстуальных коннотациях, отсылающих к «мифрологическому образу космической зоны» [5, т. 1 , c. 182] наиболее полно. До этого времени дополнительные по отношению к основному номинативному значения связывались только с денотативными характеристиками: дойная корова, бодливой корове Бог рогов не дал, сидит, как на корове седло; и с инвективным употреблением в переносном значении. После описанного периода, в советской поэзии и поэзии последних десятилетий в большинстве случаев лексема корова встречается в своем основном значении, мифропоэтические коннотации присутствуют в нем или поверхностно, возможно, вне авторской интенции, см. Тал, словно под тенью священного лавра, / Корова лежит с головой Минотавра, / Египетскил богол тал кажется дятел / И я наблюдаю, простой наблюдатель (1978, И.В. Чиннов) [9]; или поверхностно, см. Корова ли в калошах, / свяшенная корова, / индийская богиня, / полчалась прогуляться / со скотного двора? (С.В. Петров 1940) [9]; И венки из вьюнков и калелий / На рогах у свяшенных коров (А.Е. Адалис 1947) [там же]; или соответствует библейскому мотиву, см. у И.А. Бродского Звезда блестит, но ты далека. / Корова мычит, и дух молока / мешается с запахол козьей мочи, / и гролко блеет овца в ночи. / Шнурки 
башлаков и ланжеть брюк, / а вовсе не то, что есть вокруг, / мешает почувствовать мне наяву / себя младенцем в хлеву (1964) [там же].

Таким образом, если механизм коннотирования в сознании человека сам по себе - следствие его эволюции и средство развития общества как такового и разных объединений людей согласно определенному «воображаемому порядку», удваивающему материальный мир, то содержание коннотации, та информация, которая сопутствует денотативным значениям слов, позволяет на уровне семантики частично охарактеризовать тип культуры, религиозных воззрений, идеологический порядок в обществе и бытующие в определенный момент культурные установки.

Коннотативная насыщенность слов, принадлежащих к разным лексико-семантическим группам, неодинакова, а степень глубины возможной коннотации обратно пропорциональна таким качествам значения лексемы, как степень его абстрактности, детализированности и наличием в денотации компонента, наполненного эмоциями, оценками и представлениями о нематериальной стороне мира, поэтому зоонимическая лексика оказывается одной из наиболее интересных групп языкового материала для анализа культурно обусловленного коннотативного значения. Рассмотрение же абстрактной лексики, которое сокращенно приведено в начале этого раздела, напротив, демонстрирует сложность выработки научного подхода к описанию их семантики.

Мы видим, что невозможно дать однозначное единое определение отношений денотации и коннотации в лексической семантике, но сужение материала исследования позволяет сделать это с большей точностью. Назвать коннотативную семантику зоонимов второстепенной возможно только с точки зрения причинноследственных отношений на этапе возникновения, когда она отталкивалась от редерента в реальном мире. Сейчас же коннотативные свойства зоонимических лексем, наоборот, присваиваются человеком как частным референтам, так и денотативным классам сущностей. Коннотация может быть первостепенной по качественному признаку (для переносных значений зоонимов, где денотация как таковая составлена из коннотаций основного ЛСВ) и по количественному (в случаях реализации в контексте большого количества коннотативных сем). Тем не менее, роль денотативного значения очень важна. И.Р. Гальперин писал, что коннотация не отрицает денотацию, а «строится на ней и сосуществует с ней. <..> Она не может полностью заглушить “денотативный код”, поскольку именно этот код порождает всякого рода возможные (и даже невозможные) его варианты» [10, с. 16]. Единственное, что представляется возможным утверждать, - это то, что для разных слов степень отдаленности от денотата и детерминированности им является переменной величиной. Подробного рассмотрения заслуживают и особенности зависимости от денотации отдельных компонентов коннотации.

Вопрос выделения зоны денотативного значения также не является однозначно решенным, поэтому определить точно, что знак означает, а что соозначает, т. е., какие из значений сле- 
дует считать «дополнительными», возможно только при анализе каждого знака индивидуально. В первую очередь коннотативные смыслы являются именно означаемыми, а дополнительно и второстепенно или облигатор- но, — это вопрос анализа отдельных актуализаций их потенщиального объема. Взгляд на коннотацию как на явление «удвоения мира» не позволяет считать ее дополнительным и второстепенным свойством значения слова.

\section{СПИСОК ИСТОЧНИКОВ И ЛИТЕРАТУРЫ}

1. Комлев, Н.Г. Слово в речи: Денотативные аспекты. М.: Изд-во МГУ, 1992. 216 с.

2. Манн, Т. Волшебная гора / Собрание сочинений Томаса Манна. Т. 3. М.: РАМ, 1995. 479 с.

3. Мамардашвили, М.К. Лекции по античной философии. М.: Азбука-классика, 2014. 256 с.

4. Мамардашвили, М.К., Пятигорский, А.М. Символ и сознание. Метафизические рассуждения о сознании, символике и языке. М.: Языки русской культуры, 1997. URL: http://psylib. org.ua/books/mampg02/txt01.htm (дата обращения: 23.11.2019).

5. Топоров, B.H. Статьи для мифологических энциклопедий в 2 т. М.: Языки славянских культур, 2014. $1136 \mathrm{c}$.

6. Лотман, Ю.М. О проблеме значений во вторичных моделирующих системах // Учен. зап. Тарт. гос. Ун-та, 1965. Вып. 181. С. 22-37.

7. Лакофф, Д., Джкосон, М. Метафоры, которыми мы живем: пер. с англ. / под ред. и с предисл. А.Н. Баранова. М.: Едиториал УРСС, 2004. 256 с.

8. Академик. Словари и энциклопедии. URL: http:/dic.academic.ru/ (дата обращения: 17.08.2019).

9. Национальный корпус русского языка. URL: http://www.ruscorpora.ru/new/index.html (дата обращения: 3.04.2019).

10. Гальперин, И.Р. Проблемы лингвостилистики // Новое в зарубежной лингвистике. М.: Издво Иностранная литература, 1980. Вып. 9. С. 5-34.

\section{REFERENGES}

1. Akademik. Slovari i enciklopedii, available at: http://dic.academic.ru/ (accessed: 17.08.2019).

2. Galperin I.R. Problemy lingvostilistiki, Novoe v zarubezhnoj lingvistike, Inostrannaya literatura, Moscow, 1980, No. 9, pp. 5-34. (in Russian).

3. Komlev N.G. Slovo v rechi: Denotativnye aspekty. Moscow State University, 1992, 216 p. (in Russian).

4. Lakoff G., Johnson M. Metafory, kotorymi my zhivem. Moscow, Editorial URSS, 2004, 256 p. (in Russian)

5. Lotman Yu.M. O probleme znachenij vo vtorichnyh modeliruyushchih sistemah, Proceedings of Tartu State University, 1965, No. 181, pp. 22-37. (in Russian)

6. Mamardashvili M.K. Lekcii po antichnoj filosofii. Moscow, Azbuka-klassika, 2014, 256 p. (in Russian)

7. Mamardashvili M.K., Pyatigorskij A.M. Simvol i soznanie. Metafizicheskie rassuzhdeniya o soznanii, simvolike i yazyke. Moscow, Yazyki russkoj kultury, available at: http://psylib.org.ua/books/ mampg02/txt01.htm (accessed: 23.11.2018). (in Russian)

8. Mann T. Volshebnaya gora, Sobranie sochinenij Tomasa Manna, Vol. 3. Moscow, RAM, 1995, 479 p. (in Russian) 
9. Nacionalnyj korpus russkogo yazyka, available at: http://www.ruscorpora.ru/new/index.html (accessed: 3.04.2019). (in Russian)

10. Toporov V.N. Stati dlya mifologicheskih enciklopedij in 2 Vol. Moscow, Yazyki slavyanskih kultur, 2014, 1136 p. (in Russian)

Красильникова Пелагея Юрьевна, старший преподаватель, кафедра русского языка как иностранного, Институт международного образования, Российский государственный университет имени А.Н. Косыгина (Технологии. Дизайн. Искусство), krasilnikov3@gmail.com

Krasilnikova P.Yu., Senior Lecturer, Russian as Foreign Language Department, International Education Institute, A.N. Kosygin Russian State University (Technologies. Design. Art), krasilnikov3@gmail.com 